\title{
A Study of the Relationship between Internet Dependence and Social Skills of Students of Medical Sciences
}

\author{
Hossein Jenaabadi ${ }^{1} \&$ Ghazal Fatehrad $^{2}$ \\ ${ }^{1}$ Psychology Department of Education, University of Sistan and Baluchestan, Iran \\ ${ }^{2}$ MA. Degree on educational Administration. Tehran Islamic Azad University, Science and Research Branch, \\ Iran
}

Correspondence: Hossein Jenaabadi, Associate professor of Psychology Department of Education, University of Sistan and Baluchestan, Iran. E-mail: hjenaabadi@ped.usb.ac.ir

Received: November 29, 2014

Accepted: January 8, 2015

Online Published: July 6, 2015

doi:10.5539/mas.v9n8p49

URL: http://dx.doi.org/10.5539/mas.v9n8p49

\begin{abstract}
Introduction: Internet dependence is a topic of interest that has been discussed as a behavior-based addiction in recent years and has become a growing issue in the information technology era. This addiction has caused many problems for college students. In this regard, the current study aimed to investigate the relationship between Internet addiction and social skills of students of Medical Sciences.

Methods: This is a descriptive-correlational study. The sample included 354 medical students who were selected through applying stratified random sampling method and were tested using two questionnaires of Internet Addiction and Social Skills. Data were analyzed applying the Pearson correlation coefficient and stepwise regression analysis.

Results: The findings indicated that there were significant positive relationships between Internet dependence and social skills. Internet dependence has a reversed relation with initiation and termination, assertiveness, social reinforcement, empathy, and cooperation. Increasing Internet dependence, these skills weakened. However, no significant correlation was found between Internet dependence and orientation skills. Moreover, the results of the regression analysis showed that these five variables predicted about $66 \%$ of the criterion variable (internet dependence).

Conclusion: Since Internet addiction can falter students' social skills and has strong negative effects on interpersonal communication and social interaction, it is essential to make efforts to give students' use of the Internet a specific direction to avoid its probable adverse effects.
\end{abstract}

Keywords: internet, internet dependence, social skills, university students

\section{Introduction and Objective}

The essence of society is sustainable communications between human beings and communication as the first need of any system is a special form of social interaction (Doran, 2006). Nowadays, the Internet has become an essential part of everyday life around the world (Bayraktar \& Gun, 2007) and its use, especially among the young and educated, is steadily increasing (Ozcan \& Buzlu, 2007) and brings with itself various promises and threats (Mc Quail, 2005). Creating new social cohesion, increasing social isolation, reduction of social participation, Internet dependence (Mc Kenna and Bargh, 2004) and replacing social activities with the Internet (Kestenbaum et al., 2002) are among the numerous effects of the Internet. These effects are so extensive and widespread that some researchers consider the role of the Internet in today's life as the role of electricity in the industrial revolution (Liesler et al., 2002).

Internet dependence is an interesting issue being recently considered as a behavior-based addiction (Mohammad-beigi et al., 2010) and has become the growing issue of the information technology era (Davis and Besser, 2002; Hur, 2006). Internet dependence refers to one's inability to control himself/herself in using the Internet which gradually leads to create uncomfortable feelings, debilitation of daily functional activities (Shapira et al., 2003; Douglas et al., 2008) and eventually mental disturbance or stress (Weinstiein and Lejoyeux, 2010). Douglas et al. introduced Internet dependence as an obsessive-compulsive use of the Internet, that if the individual is excluded from such use, he/she becomes so irritated and shows behaviors with tantrum (Douglas et 
al., 2008). Internet dependence is associated with symptoms such as anxiety, depression, irritability, obsessive thoughts, isolation and disruption of social relations (Kooraki et al., 2012).

On the other hand, it seems that Internet dependence influences individuals' social skills (Preece, 2000; Wellman and Gulia, 1999). Social skills are a series of purposeful, interrelated behaviors based on the status, which are acquired and are under the control of individuals (Momayezi et al., 2011). Social skills are important factors in shaping relationships, enhancing the quality of social interaction and even mental health of individuals. These skills can be defined as a perfect model of behaviors exhibited by an individual in interpersonal relations (Teodoro, 2005). Social skills encompass a variety of capabilities and capacities including emotional expression, self-regulation, social flexibility, social sensitivity, assertiveness (Segrin \& Taylor, 2007). Emotional expression is defined as the ability to understand and express emotions in interpersonal relationships. Self-regulation is an integrated behavioral process consisted of useful behaviors for learning. Social sensitivity is defined as the ability to decode non-verbal signs and social flexibility is the ability to inhibition emotions of self in stressful conditions. Assertiveness is another social skill that enables an individual to act in favor of him/herself and express his/her feelings honestly without abusing others' rights (Kooraki et al., 2012).

Since Internet connections, unlike face to face communication, are more flexible and individuals can easily remove or edit their negative information, such relationships continue and lead to shortcomings in social skills. A study on the relationship of social self-efficacy, locus of control and Internet addiction among students revealed that there was a negative relationship between social self-efficacy and Internet addiction (Iskender and Akin, 2010). During the past decade, the number of studies conducted on Internet addiction has increased rapidly (Bayraktar \& Gun, 2007; Yen et al., 2007; Kubey, Lavin and Barrows, 2001). For example, researchers found significant relationships between Internet dependence, anxiety, restlessness, aggression and hostility (Yen et al., 2007), drugs experience (Yen et al., 2007; Ko et al, 2006), losing control and endurance, retreat, performance disorder, reduction of decision-making ability (Ko et al, 2005), loneliness (Kraut et al., 1998; Nalwa and Anand, 2003), sensation seeking (Lin \& Tsai, 2002), poor mental health (Yang, 2001), reduction of family communications (Armstrong, Phillips and Saling, 2000), reduction of students' GPA and their educational failure (Mohammad-beigi et al., 2010), low self-concept (Shoa Kazemi, 2008), reduction of social communications circle (Young and Rogers, 1998), loss of social skills and social isolation (Moody, 2004; Whitty and McLaughlin, 2007), low social quality of learners (Nadi \& Sajjadian, 2010) and low social skills (Kooraki et al., 2012), etc.

In many countries, medical university students form a substantial group of Internet users (Lazinger, Bar-Ilan and Peritz, 1997; Salkovic-Petrisic et al., 2001) and this group of the users see the Internet as a reliable source (Eitel, Yankowitz and Ely, 1998) and use it for personal as well as professional goals (Scheleyer, Spallek and Torres-Urquidy, 1998; Mohagheghzadeh and Abdollahi, 2002). However, in spite of multitudes of benefits and capacities for its users, it seems this technological and information tool has attracted youth's attention and lead them to spend long hours at the computer that results in hindering from other aspects of life especially social activities. Given the young age structure of the country and considering that the youth are the most vulnerable stratum of the society against risky behaviors such as improper use of the computer and the Internet, obviously each damage to their physical and mental health and also reduction of the abilities of this active group, inevitably leads to slowing down the progress of the society. On the other hand, in the long-term, their physical and mental health may have negative effects on the health of the whole people of the society. Statistics in Iran (2004) indicated that the number of the Internet users was more than 6 million and this number is increasing day by day (Sadeghian, 2008). Considering the increasing use of the Internet in Iran especially by the youth and the adolescent, if preventive measures are not foreseen, soon we will witness an increase in problems of this area especially Internet dependence. However, very few studies are conducted on the subject. Therefore, there is an emergent need to carry out more extensive, detailed and rigorous research on Internet dependence and social skills.

In many countries, medical university students form a substantial group of Internet users (2001) and this group of the users see the Internet as a reliable source (1998) and use it for personal as well as professional goals (2006). However, in spite of multitudes of benefits and capacities for its users, it seems this technological and information tool has attracted youth's attention and lead them to spend long hours at the computer that results in hindering from other aspects of life especially social activities. Given the young age structure of the country and considering that the youth are the most vulnerable stratum of the society against risky behaviors such as improper use of the computer and the Internet, obviously each damage to their physical and mental health and also reduction of the abilities of this active group, inevitably leads to slowing down the progress of the society. On the other hand, in the long-term, their physical and mental health may have negative effects on the health of the whole people of the society. Statistics in Iran (2004) indicated that the number of the Internet users was more 
than 6 million and this number is increasing day by day (2013). Considering the increasing use of the Internet in Iran especially by the youth and the adolescent, if preventive measures are not foreseen, soon we will witness an increase in problems of this area especially Internet dependence(2014). However, very few studies are conducted on the subject(2013). Therefore, there is an emergent need to carry out more extensive, detailed and rigorous research on Internet dependence and social skills(2014). Thus, in this regard, the present study sought to answer the question that whether there is any relationship between dimensions of social skills and Internet dependence among students and what is the contribution of each dimension of social skills in prediction of Internet dependence?

\section{Methods and Materials}

Since it examines the relationships between the variables, this is a descriptive-correlational study. The population consisted of all medical science students of Islamic Azad university of Tehran, Sciences and Research Branch $(\mathrm{N}=4277)$, among which based on the Cochran's formula, 354 students were selected using stratified random sampling method (to place on the sample students from all fields and branches of medical sciences). Sample participants included 212 female students and 142 male students. Two tools were used in this study.

A) Social Skills Inventory: The inventory was designed and developed by Abbasi for higher education in 2003. The inventory has 143 items. It was standardized on 142 female students and 212 male students. Subjects should specify their response among a 5-point Likert type scale, (always, quite often, sometimes, rarely and never). Six factors including initiation and termination, self-assertiveness, social reinforcement, empathy, orientation and cooperation are analyzed. The internal consistency of the inventory was calculated using the Cronbach's alpha that was 0.96 and standardized scores of $t$ and $\mathrm{z}$ were calculated on two groups of male and female subjects of Ahvaz Azad University that revealed good construct validity and predictive power (Harjy et al., 2005).

B) Internet Addiction Test: The instrument is developed and standardized by Young (Kimberly, 2007). The test consists of 20 items and subjects should specify their response among a 5-point Likert-type scale, (always, often, sometimes, rarely, does not apply to me). The internal consistency of the test was calculated using the Cronbach's alpha that was 0.92 . It also has a good construct validity and predictive power. In the present study, before the final run, a pilot study was implemented on a sample of 50 students which revealed that the test is reliable at the alpha level of 0.01 with the Cronbach's alpha of 0.92 which indicates that the reliability coefficient is high.

\section{Results}

Q1: Is there any significant relationship between dimensions of social skills and Internet dependence among students?

Before proceeding to the test results, first descriptive statistics are presented in Table 1.

Table 1. Descriptive characteristics of the variables

\begin{tabular}{llllll}
\hline Variable & Mean & SD & Variance & Skewness & Kurtosis \\
\hline Internet dependence & $77 / 1$ & $682 / 0$ & $466 / 0$ & $50 / 0$ & $09 / 0-$ \\
Initiation and termination skills & $71 / 2$ & $601 / 0$ & $361 / 0$ & $44 / 0-$ & $14 / 0$ \\
Assertiveness skills & $54 / 2$ & $549 / 0$ & $302 / 0$ & $64 / 0-$ & $54 / 0$ \\
social reinforcement skills & $92 / 2$ & $645 / 0$ & $416 / 0$ & $87 / 0-$ & $47 / 1$ \\
Orientation Skills & $54 / 2$ & $656 / 0$ & $430 / 0$ & $59 / 0-$ & $62 / 0$ \\
Empathy skills & $76 / 2$ & $647 / 0$ & $419 / 0$ & $15 / 0-$ & $84 / 1$ \\
cooperation skills & $76 / 2$ & $647 / 0$ & $419 / 0$ & $48 / 1-$ & $17 / 1$ \\
\hline
\end{tabular}

Mean and standard deviation values in the above table indicate the appropriate dispersion and Skewness and Kurtosis indices indicate a normal distribution of the variables. The above table also indicates that among the dimensions of social skills, the highest scores goes for the component of social reinforcement skills (2.92) and the lowest scores goes for the components of assertiveness skills (2.54) and orientation skills (2.54). The Pearson correlation test was used to examine the hypothesis. The results are presented in Table 2. 
Table 2. Correlation coefficients of Internet dependence and social skills

\begin{tabular}{lll}
\hline Variable & Internet addiction & Sig \\
\hline Initiation and termination skills & $152 / 0-$ & $01 / 0$ \\
Assertiveness skills & $143 / 0-$ & $01 / 0$ \\
Social reinforcement skills & $185 / 0-$ & $001 / 0$ \\
Orientation Skills & $091 / 0-$ & $08 / 0$ \\
Empathy skills & $183 / 0-$ & $001 / 0$ \\
Cooperation skills & $133 / 0-$ & $01 / 0$ \\
\hline
\end{tabular}

The table above indicates that the results of all dimensions of social skills except for orientation skills have significant negative correlation with Internet dependence. Negative correlation indicates that the increase of Internet dependence among students reduces their social skills and vice versa.

Q2: what is the contribution of each dimension of social skills in prediction of Internet dependence?

To answer this question a stepwise multiple regression analysis was used. In the first step, the variable of empathy skills, in the second step, initiation and termination skills, in the third, assertiveness skills, in the fourth social, reinforcement skills and in the fifth step, cooperation skills entered into the equation and maintained their significance in five steps. Only the variable of orientation skills was not significant, and removed from the equation. The results of the regression analysis are reported in Table 3.

Table 3. Results of stepwise regression analysis of Internet dependence from predictor variables

\begin{tabular}{|c|c|c|c|c|c|c|c|c|c|c|}
\hline Predictor variable & $\mathrm{R}$ & $\mathrm{R}^{2}$ & $\Delta r^{2}$ & SE & $\mathrm{df}$ & $\mathrm{F}$ & $\Delta \mathrm{f}$ & B & Beta & $\mathrm{T}$ \\
\hline Empathy skills & $66 /$. & $44 /$. & $44 /$. & $32 / 5$ & $352 / 1$ & $* * * 61 / 280$ & $61 / 280$ & $31 / .-$ & $* * * 87 / .-$ & $86 / 17-$ \\
\hline $\begin{array}{l}\text { Initiation and } \\
\text { termination skills }\end{array}$ & $73 /$. & $54 /$. & $10 \%$ & $82 / 4$ & $351 / 1$ & $* * * 32 / 210$ & $33 / 78$ & $50 / .-$ & $* * * 49 / .-$ & $85 / 13-$ \\
\hline Assertiveness skills & $76 /$. & $58 /$. & $04 /$. & $62 / 4$ & $350 / 1$ & $* * * 86 / 162$ & $45 / 31$ & $29 / .-$ & $* * * 35 / .-$ & $97 / 8-$ \\
\hline $\begin{array}{l}\text { social reinforcement } \\
\text { skills }\end{array}$ & $78 /$. & $62 /$. & $04 /$. & $44 / 4$ & $349 / 1$ & $* * * 83 / 139$ & $11 / 30$ & $30 / .-$ & $* * * 31 / .-$ & $83 / 6-$ \\
\hline $\begin{array}{l}\text { Orientation Skills } \\
* * * p<0.001\end{array}$ & $81 /$. & $66 /$. & $04 /$. & $18 / 4$ & $348 / 1$ & $* * * 31 / 135$ & $66 / 45$ & $45 / .-$ & $* * * 26 / .-$ & $76 / 6-$ \\
\hline
\end{tabular}

Stepwise regression analysis results in Table 3 indicate that empathy skills predicted $44 \%$ of the variance of Internet dependence. Initiation and termination skills, assertiveness skills, social reinforcement skills and cooperation skills predicted $10 \%, 4 \%, 4 \%$, and $4 \%$ of the variance of Internet dependence, respectively. These five variables predict a total of $66 \%$ of criterion variable variance. ANOVA results presented in the above table and the significance $f$ value indicates that these five variables have a significant effect on Internet dependence. Due to the beta coefficient which is negative, it can be argued that students, who have high scores on measures of social skills, are more dependent on the Internet and vice versa.

\section{Discussion and Conclusion}

The present study aimed to investigate the relationship between Internet dependence and social skills of students. To examine the research hypotheses, the Pearson correlation and stepwise multiple regression were used. In the following, the results of these two tests used to explain each of the dimensions of social skills, are discussed separately. Results of the present study about the reduction of social skills among students in the light of Internet dependence are consistent with the results of Kooraki et al. (2012) Young and Rogers (1998), Moody (34), Whitty et al. (2007) and Nadi and the Sajjadian (2010).

As the findings indicated, there was a significant negative relationship between Internet dependence and initiation and termination skills. Therefore, if students' Internet dependence increases, their initiation and termination skills decreases. Results of regression analysis revealed that this component predicted $10 \%$ of the variance of Internet dependence. According to the results of the statistical data analysis, it seems that the relationship of Internet dependence and initiation and termination skills resulted from the interventions in learned behaviors. Verbal and non-verbal behaviors cause individuals' interactions with others. Excessive use of the Internet makes a person use less verbal behavior and progressively his speech is impaired and his/her contact with the outside fades. Increased Internet use increases loneliness, depression, and social isolation. It also affects 
one of the verbal skills, i.e., initiating and terminating a social conversation (Kraut et al., 1998; Nalwa and Anand, 2003).

In the current study, the relationship between Internet dependence and assertiveness skills was also negative. Multiple regression analysis also suggested that this component was able to predict $4 \%$ of the variance of Internet dependence. Assertiveness is another social skill that enables an individual to act in favor of him/herself and express his/her feelings honestly without abusing others' rights. Such an individual is able to stand on his/her own feet, show his/her true feelings honestly and simply reject unreasonable requests. These individuals have more control over their own lives and have firm and steadfast personalities. The statistical data suggested that there was a significant negative relationship between Internet dependence and assertiveness that means individuals who are addicted to the Internet lose such characteristics and cannot firmly reject unreasonable requests. The study found that increased Internet usage reduces the ability of assertiveness. However, the relationship was not robust and other variables were not controlled.

The findings also suggested that increased dependence on the Internet among students decreased their social reinforcement skills (another dimension of social skills). The predictive power of this component was $4 \%$. It should be argued that Internet dependence and social reinforcement skills arise from positive reinforcements that the Internet suggests. Strengthening social relationships on the side of family and friends increases and maintains interaction and marks interest in the ideas, thoughts and feelings of other people. When individuals do not receive reward or reinforcement from their family or the society and their interests and emotions are reacted through the Internet, they prefer to answer to such reinforcements and thus their addiction to the Internet rises and they withdraw from friends and the community.

However, the important point in investigating social skills is the fact that unlike other dimensions, no significant relationship was observed between orientation skills and Internet dependence. Regression results indicated the inability of this component to predict Internet dependence. The lack of correlation between the above variables can be explained in this way that leading individuals have more ability and talent compared to their peers, they have higher confidence and morale and can lead a group. Acquiring such an ability arises either from their family in which some responsibilities are taken by the individual or their academic discipline (Kooraki et al., 2012). Individuals with orientation skills do their own tasks and duties without other's help, since the ability of doing things independently has made them responsible and aware of their own ability and talent and this leads to high confidence. Extroverts receive more social support than introverts. Individuals with strong social ties use the Internet in order to complement and strengthen their communication. Considering the statistical results, leading individuals are not Internet dependence and use the Internet positively to complement their communication.

In addition, the present study indicated a significant negative relationship between Internet dependence and empathy skills. According to statistical results, it is found that dependence to the Internet reduced individuals' empathy skills. Individuals without empathy skills can hardly understand others' emotions and discomforts, they cannot feel others' sorrow, and they try to be seen as less as possible in the community which leads to their withdrawal and isolation. Therefore, Internet dependence is associated with separation from community and spending more time on the Internet (Moody, 2004).

Finally, based on the results, there was a significant negative relationship between cooperation skills and Internet dependence. It can be argued that cooperation skills are among acquired skills, such as the ability to ask others' help and effective communication so that this connection is acceptable, valuable and lucrative for both parties. The time spent on an activity inevitably leads to lower time on similar activities. Thus, there is still concern that the use of the Internet, especially non-social uses, such as web surfing, spending much time on the Internet, is associated with a decrease in social activities including cooperation skills which eventually leads to social isolation. Such individuals refuse to participate in group activities and avoid collaboration with peers. An increase in Internet dependence decreases cooperation skills.

Today, social skills are highly regarded; so that in social and educational systems if individuals lack social skills, they are often labeled inappropriately and are considered as people with social problems. Inability in social skills even creates problems in terms of academic achievement, because lack of such skills may destroy self-worth and self-esteem and make the individual seem different from others or be considered as abnormal. In such a situation, the individual is easily excluded and loses desirable positions for development along with his/her peers. However, one of the factors that could cause impairment or loss of social skills may be Internet dependence.

Although the development of electronic devices and the Internet is remarkable in all scenes, today's modern civilized man needs to appropriately use these electronic means, including the Internet in order to avoid flaws in his social relations. Excessive use of the Internet and severe interest in it causes Internet dependence. It seems 
that one of the factors that led to significant relationship between Internet dependence and social skills is the lack of the mentioned skills on the side of students. Internet dependence causes disorders in life, loss of social skills or social isolation. Overall, the results of this study suggested that there was a significant negative relationship between Internet dependence and students' social skills. Therefore, it can be concluded that Internet dependence decreases students' social skills.

\section{References}

Autor, D. H., \& David, D. (2013). The Growth of Low-Skill Service Jobs and the Polarization of the U.S. Labor Market. American Economic Review, 103(5), 1553-97. http://dx.doi.org/10.1257/aer.103.5.1553

Azher, M., Behram K. R., Salim, M., Bilal, M., Hussain, A., \& Haseeb, M. (2014). The Relationship between Internet Addiction and Anxiety among students of University of Sargodha. International Journal of Humanities and Social Science, 4(1).

Cho, Sung, Shin, Lim and Shin (2013). Does psychopathology in childhood predict internet addiction in male adolescents? Child Psychiatry Hum Dev., 44(4), 549-555. http://dx.doi.org/10.1007/s10578-012-0348-4

DeMatteo, F. J., Arter, P. S., Sworen-Parise, C., Faseiana, M., \& Panihamus, M. A. (2012). Social Skills Training for Young Adults with Autism Spectrum Disorder: Overview and Implications for Practice. National Teacher Education Journal, 5(4), 57-65

Heckman, James, J., \& Kautz, T. (2012). Hard Evidence on Soft Skills. Labour Economics, 19, 4451-464. http://dx.doi.org/10.1016/j.labeco.2012.05.014

Hillary, A. (2013). Problematic Internet Use among Persons with Social Anxiety Disorder. PloS One, 8(2), e57831. http://dx.doi.org/10.1371/journal.pone.0057831

Hong , Zalesky, Cocchi, Fornito, Choi , Kim , Suh, Kim , Kim and Yi (2013). Decreased functional brain connectivity in adolescents with internet addiction. PloS One, 8(2), e57831. http://dx.doi.org/10.1371/journal.pone.0057831.

Tankersley, M., \& Cook, B. (Eds.) (2013). Effective practices in special education. Boston, MA: Pearson.

Armstrong, L., Phillips, J., \& Saling, L. (2000). Potential determinants of heavier internet usage. International Journal of Human-Computer Studies, 53, 537-550. http://dx.doi.org/10.1006/ijhc.2000.0400

Bayraktar, F., \& Gun, Z. (2007). Incidence and correlates of internet usage among adolescents in North Cyprus. Cyber Psychology \& Behavior, 10(2), 191-197. http://dx.doi.org/10.1089/cpb.2006.9969

Davis, R., Flett, G., \& Besser, A. (2002). Validation of a new scale for measuring problematic Internet use: Implications for pre-employment screening. Cyber Psychology and Behavior, 5(4), 331-345. http://dx.doi.org/10.1089/109493102760275581

Doran, B. (2006). Effect of cybernetic space on identity. PHD Thesis's. Field of Sociology. University of Teacher Training Tehran.

Douglas, A., Mills, J., Niang, M., Stepchenkova, S., Byund, S., \& Ruffini, C. (2008). Internet addiction: Meta-synthesis of qualitative research for the decade 1996-2006. Computers in Human Behavior, 24(6), 3027-44. http://dx.doi.org/10.1016/j.chb.2008.05.009

Douglas, A. C., Mills, J. E., Niang, M., Stepchenkova, S., Byun, S., Ruffini, C., ... Blanton, M. (2008). Internet addiction: Meta-synthesis of qualitative research for the decade 1996-2006. Computers in Human Behavior, 24, 3027-3044. http://dx.doi.org/10.1016/j.chb.2008.05.009

Eitel, D. R., Yankowitz, J., \& Ely, J. W. (1998). Use of internet technology by obstetricians and family physicians. JAMA, 280(15), 1306-7. http://dx.doi.org/10.1001/jama.280.15.1306

Harjy, U. et al. (2005). Social skills in interpersonal communication. (Translation Khashayar Beigi and Merdad Firuz bakht). Tehran: growth.

Hur, M. (2006). Demographic, habitual, and socioeconomic determinants of Internet addiction disorder: An empirical study of Korean teenagers. Cyber Psychology and Behavior, 9(5), 514-525. http://dx.doi.org/10.1089/cpb.2006.9.514

Iskender, M., Akin, A. (2010). Social self-efficacy, academic locus of control, and internet addiction. Computers \& Education, 54, 1101-1106. http://dx.doi.org/10.1016/j.compedu.2009.10.014

Kestenbaum, M., Robinson, G. P., Neustadtl, A., \& Alvarez, A. (2002). Information technology and social time displacement. IT\& society, 1(1), 21-37 Retrieved from http://www.Itand society.org 
Kiesler, S., Kraut, R., Cummings, J., Boneva, B., Helgeson, V., \& Crawford, A. (2002). Internet evolution and social impact. IT\& society, l(1), $120-134$.

Kimberly, Y. (2007). Internet Addiction Test (IAT). Retrieved from http://www. netaddiction. com/ index.php

Ko, C. H., Yen, J. Y., Chen, C. C., Chen, S. H., \& Yen, C. F. (2005). Gender differences and related factors affecting online gaming addiction among Taiwanese adolescents. Journal of Nervous and Mental Disease, 193(4), 273-277. http://dx.doi.org/10.1097/01.nmd.0000158373.85150.57

Ko, C., Yen, J., Chen, C., Chen, S., Wu, K., \& Yen, C. (2006). Tri-dimensional personality of adolescents with internet addiction and substance use experience. Canadian Journal of Psychiatry, 51(14), 887-894.

Kooraki, M., Yazdkhasti F., Ebrahimi A., Oreizi H. R. (2012). Effectiveness of Psychodrama in Improving Social Skills and Reducing Internet Addiction in Female Students. Iranian Journal of Psychiatry and Clinical Psychology, 17(4), 279-288.

Kraut, R., Patterson, M., Lundmark, V., Kiesler, S., Mukopadhyay, T., \& Scherlis, W. (1998). Internet paradox: A social technology that reduces social involvement and psychological well-being. American Psychologist, 53(9), 1017-1031. http://dx.doi.org/10.1037/0003-066X.53.9.1017

Kubey, R., Lavin, M., \& Barrows, J. (2001). Internet use and collegiate academic performance decrements: Early findings. Journal of Communication, 51, 366-382. http://dx.doi.org/10.1111/j.1460-2466.2001.tb02885.x

Lazinger, S.S., Bar-Ilan, J., Peritz, B.C. (1997). Internet use by faculty members in various disciplines: a $\begin{array}{lllll}\text { comparative } \quad \text { case } & \text { study. } & \text { JASIS, } & 48(6), & 508-18 .\end{array}$ http://dx.doi.org/10.1002/(SICI)1097-4571(199706)48:6<508::AID-ASI4>3.0.CO;2-Y

Lin, S. S. J., \& Tsai, C. C. (2002). Sensation seeking and internet dependence of Taiwanese high school adolescents. Computers in Human Behavior, 18, 411-426. http://dx.doi.org/10.1016/S0747-5632(01)00056-5

Mc Kenna, K. Y. A., \& Bargh, J. A. (2004). Plan9: from cyberspace. The implication of the internet for personality and social psychology. Personality and social psychology review, 4(1), 57-75. http://dx.doi.org/10.1207/S15327957PSPR0401_6

Mc Quail, D. (2005). Mc Quail’s mass communication theory, 5th edition. Sage publications. London.

Mohagheghzadeh, M. S., \& Abdollahi, M. (2002). Scopes and using type of internet center members of Shiraz University of Medical Sciences about center facilities and its impact on research works of them. Communication sciences, 18(1, 2), 1-10.

Mohammad-beigi, A., Ghazavi, A., Mohammad-salehi, N., Ghamari, F., \& Saeedi, A. (2010). Effect of internet addiction on educational status of Arak University of medical sciences students, spring 2009. Arak Medical University Journal (AMUJ), 12(4, Supp 1), 95-102.

Momayezi, F., Abdi Zarrin S., Eglima M., Raheb Gh. (2011). Social Skills: The Role of this Skills in Prevention of Adolescents Abuse. Journal of Tolooe Behdasht, 10(1), 96-108.

Moody, E. J. (2004). Internet use and its relationship to lineless. Cyber Psychology \& Behavior, 4(3), 393-401. http://dx.doi.org/10.1089/109493101300210303

Nadi MA, \& Sajjadian I. (2010). Path analysis of relationship between personality traits and internet addiction with quality of life of internet users in Isfahan city. Journal of Behavioral Sciences, 8(1), 34-45.

Nalwa, K., \& Anand, A. (2003). Internet addiction in students: A cause of concern. CyberPsychology \& Behavior, 6(6), 653-656. http://dx.doi.org/10.1089/109493103322725441

Ozcan, N. K., \& Buzlu, S. (2007). Internet use and its relation with the psychosocial situation for a sample of university students. Cyber Psychology \& Behavior, 10, 767-772. http://dx.doi.org/10.1089/cpb.2007.9953

Preece, J. (2000). Online communities: Designing usability, supporting sociability. Chichester: Wiley.

Sadeghian, E. (2008). Effect of computer and internet on children and teenagers. Iran doc Scientific Communication Monthly Journal, 4(4), 78-86.

Salkovic-Petrisic M, Mrzljak A, Lackovic Z. (2001). Usage of the internet pharmacology resources among European Pharmacologists: a preliminary investigation. Fundam Clin Pharmacol, 15(1), 55-60. http://dx.doi.org/10.1046/j.1472-8206.2001.00002.x

Schleyer, T.K., Spallek, H., Torres-Urquidy, M.H. (1998). A profile of current internet users in dentistry. $J$ Am 
Dent Assoc, 129(12), 1748-53. http://dx.doi.org/10.14219/jada.archive.1998.0146

Segrin, C., \& Taylor, M. (2007). Positive interpersonal relationships mediate the association between social skills and psychological well-being. Personality and Individual Differences, 43, 637-646. http://dx.doi.org/10.1016/j.paid.2007.01.017

Shapira, N., Lessig, M., Goldsmith, T., Szabo, S., Lazoritz, M., \& Gold, M. (2003). Problematic Internet use: Proposed classification and diagnostic criteria. Depression and Anxiety. Computers in Human Behavior, 17(4), 207-16. http://dx.doi.org/10.1002/da.10094

Shoa Kazemi, M. (2008). A comparison of chat behavior and its relation with self- concept university student (s) academic year from 2006 - 2007. Journal of Psychological Studies, 4(2), 27 - 36.

Teodoro M. L. \& Kappler Ch, Rodrigues J. L, et al. (2005). The Matson Evaluation of Social Skill with Youngsters, (MESSY) \& its Adaptation for Brazilian Children \& Adolescents. Interamerican Journal of Psychology, 39(22), 239-246.

Weinstein, A., \& Lejoyeux, M. (2010). Internet addiction or excessive internet use. American Journal of Drug \& Alcohol Abuse, 36, 277-283. http://dx.doi.org/10.3109/00952990.2010.491880

Wellman, B., \& Gulia, M. (1999). Net surfers don't ride alone: Virtual communities as communities. In P. Kollock \& M. Smith (Eds.), Communities and Cyberspace. New York: Routledge.

Whitty, M. T., \& McLaughlin, D. (2007). Online recreation: The relationship between loneliness, Internet self-efficacy and the use of the internet for entertainment purpose. Computers in Human Behavior, 23, 1435-1446. http://dx.doi.org/10.1016/j.chb.2005.05.003

Yang, C. K. (2001). Sociopsychiatric characteristics of adolescents who use computers to excess. Acta Psychiatric a Scandinavica, 104, 217-222. http://dx.doi.org/10.1034/j.1600-0447.2001.00197.x

Yen, J., Ko, C., Yen, C., Wu, H., \& Yang, M. (2007). The co morbid psychiatric symptoms of internet addiction: Attention deficit and hyperactivity disorder (ADHD), depression, social phobia, and hostility. Journal of Adolescent Health, 41, 93-98. http://dx.doi.org/10.1016/j.jadohealth.2007.02.002

Young, K. S., \& Rogers, R. C. (1998). The relationship between depression and internet addiction. Cyber Psychology \& Behavior, 1, 25-28. http://dx.doi.org/10.1089/cpb.1998.1.25

\section{Copyrights}

Copyright for this article is retained by the author(s), with first publication rights granted to the journal.

This is an open-access article distributed under the terms and conditions of the Creative Commons Attribution license (http://creativecommons.org/licenses/by/3.0/). 